\title{
Nonlinear Adaptive Control for Wind Turbine Under Wind Speed Variation
}

\author{
Abdelhaq Amar Bensaber', Mustapha Benghanem², Mohammed.Amar Bensaber ${ }^{3}$, \\ Abdelmadjid Guerouad ${ }^{4}$ \\ ${ }^{1,2,4}$ AVCIS Laboratory, Oran University of Science and Technology , Mohamed Boudiaf, Algeria \\ ${ }^{3}$ School of Computer Science 08 May 1945 Sidi Bel Abbes, Algeria
}

\section{Article Info \\ Article history: \\ Received Jan 3, 2018 \\ Revised Apr 12, 2018 \\ Accepted Apr 26, 2018}

\section{Keyword:}

ASMC

MPPT

PMSG

SMC

TANH

\begin{abstract}
Wind turbines components work as nonlinear systems where electromechanical parameters change frequently [1], which makes nonlinear control an interesting solution to prevail good efficiency. SMC has been largely used in electrical power applications because it offers interesting features like robustness to parametric uncertainties and external disturbances, to conquer the biggest drawback of the SMC, adaptation strategy consists on updating the sliding gain and the turbine torque to contribute with some important characteristics such as chatter-free performance, heftiness, robustness and secure power system operation. Matlab tests are introduced and compared.
\end{abstract}

Copyright (C) 2018 Institute of Advanced Engineering and Science. All rights reserved.

\section{Corresponding Author:}

Abdelhaq Amar Bensaber,

AVCIS Laboratory,

Oran University of Science and Technology,

Mohamed Boudiaf, Algeria

Email: abs.abdelhak@gmail.com

\section{INTRODUCTION}

Nowadays, Wind Turbines have become one of the important topics and treated as a future technology because it's clean, free, reliable and it efficiency [2,3]. Thus, those factors became important topics in industry and research [4,5]. Accordingly, control approaches are required to fulfil ultimate performance. The PMSG-WT has been one of popular wind power systems [6] due to the simpler structure, robustness, lower maintenance costs, elimination of gearbox and high effectiveness $[7,8]$. Several methods are introduced to achieve maximum performances like the vector control theory accompanied by classical control techniques [9] but this controllers can serve a good performance only under ideal grid voltage conditions and can't handle the inaccuracies. Furthermore, these controllers may provide insufficient performance for different operating points. Therefore, papers have presented different control schemes like SMC [10-12], HOSMC [13-15], advance control techniques [16-18].

Due to the strong nonlinearities originated from the aerodynamics, nonlinear control methodologies gained attraction such us backstepping $[19,20]$ because it's many features like high accuracy, fast dynamic response, stability and simplicity [21]. However, it can't handle parametric precariousness and exterior disturbances. Fortunately, SMC can conquer that problem because it's robust and respect parameters variations. Standard SMC it suffers two main deficiencies. First, chattering phenomenon which produced from the high-frequency switching that damage the performance and excites high frequency vibrations $[22,23]$ to overthrown these problems, many authors proposed to modify the SMC law [24-26] like approximating the sign function by a high gain saturation function [27]. In an attempt to exploit the advantages of the SMC, an adaptive sliding mode controller is developed to track the rotor speed for 
maximum power the adaptation algorithms are developed, where the sliding gain is updated based on the sliding surface and its derivative, and the turbine torque, considered unknown by the controller, is developed by using the sliding mode control itself. The adaptive part constitutes the major contribution of this work. Results are presented and discussed to show that controllers as ASMC can improve performances of PMSG in terms of reference tracking, sensibility to perturbations and parameters variations. In this article: turbine model and the MPPT are in the section II. In part III, PMSG mathematical model is introduced. Section IV introduces SMC. In section V ASMC is proposed. At last, matlab results are given and debated.

\section{TURBINE MODEL:}

The power contained in kinetic energy form at a speed Vv, surfaceA1, is expressed by (1) [28]:

$$
P_{v}=\frac{1}{2} \rho A_{1} V_{v}^{3}
$$

Where $\rho$ is the air density, but WT can regain just a part of that power as shown in (2):

$$
P_{v}=\frac{1}{2} \rho \pi R^{2} V_{v}^{3} C_{p}
$$

Where: Cp is power coefficient [24].The speed ratio $\lambda$ introduced by (3):

$$
\lambda=\frac{R \Omega_{t}}{V_{v}}
$$

Where R: blades length, $\Omega_{t}$ : rotor speed. The theoretical extreme rate of Cp is Betz limit:

$$
C_{p_{-} \text {theo_max }}=0,593=59,3 \%
$$

The torque and power coefficient is represented in function of tip step ratio $(\lambda)$ and the pitch angle $(\beta)$ as shown in $(4,5)$ :

$$
\begin{aligned}
& C_{p}=C_{1}\left(\frac{C_{2}}{\lambda_{i}}-C_{3} \beta-C_{4} \beta^{C_{5}}-C_{6}\right)\left(e^{C_{7} / \lambda_{i}}\right) \\
& \lambda_{i}=\frac{1}{\lambda+C_{8}}
\end{aligned}
$$

The slow shaft mechanical torque Ct is expressed by (6):

$$
C_{t}=\frac{P_{t}}{\Omega_{t}}=\frac{\pi}{2 \lambda} \rho R^{3} v^{2} C_{p}
$$

Mechanical system: Mechanical model will be represented in Figure 1.

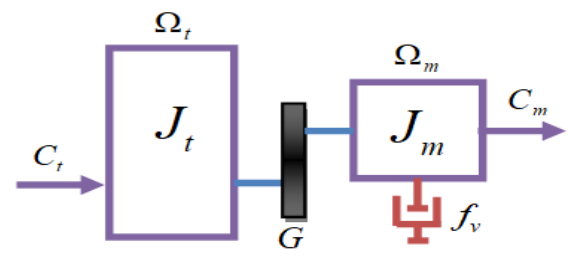

Figure 1. Mechanical model 
Where: Jt: the turbine inertia, while Jm: generator inertia, G: gearbox ratio. The generator speed and the fast shaft torque as shown in (7-9):

$$
\begin{aligned}
& \Omega_{m}=G \Omega_{t} \\
& C_{m}=C_{t} / G
\end{aligned}
$$

Next,

$$
C_{m}-C_{e m}=\left(\frac{J_{t}}{G^{2}}+J_{m}\right) \frac{d \Omega_{m}}{d t}+f_{v} \Omega_{m}
$$

\section{PMSG MATHEMATICAL MODEL:}

PMSG mathematical model in the dq reference as shown in (10-11) [29]:

$$
\begin{aligned}
& U_{d}=R_{s} I_{d}+L_{d} \frac{d i_{d}}{d t}-L_{q} i_{q} \omega_{r} \\
& U_{q}=R_{s} I_{q}+L_{q} \frac{d i_{q}}{d t}+\left(L_{d} i_{d}+\phi_{m}\right) \omega_{r}
\end{aligned}
$$

Thus, (10) - (11) can be indicated by (12-13):

$$
\begin{aligned}
& \frac{d i_{d}}{d t}=-\frac{R_{s}}{L_{d}} i_{d}+\frac{L_{q}}{L_{d}} \omega_{r} i_{q}-\frac{1}{L_{d}} U_{d} \\
& \frac{d i_{q}}{d t}=-\frac{R_{s}}{L_{q}} i_{q}-\frac{L_{d}}{L_{q}} \omega_{e} i_{d}-\frac{1}{L_{q}} U_{q}+\frac{1}{L_{q}} \phi_{m} \omega_{r}
\end{aligned}
$$

The motion equation as shown in (14-15):

$$
\begin{gathered}
C_{\text {em }}-C_{r}=J \frac{d}{d t} \omega_{r}+f_{v} \omega_{r} \\
J=\frac{J_{\text {turbine }}}{G^{2}}+J_{g}
\end{gathered}
$$

Rotational speed as shown in (16):

$$
\frac{d \omega_{r}}{d t}=\frac{1}{J}\left(C_{m}-C_{e m}-f \omega_{r}\right)
$$

Where: $\mathrm{Cr}$ is the load torque $\mathrm{J}$ is total inertia, $\omega \mathrm{r}$ is mechanical speed.

\section{THE SLIDING MODE CONTROL}

The advantage of this approach is its simplicity and robustness in spite of system unpredictability and exterior disturbances, furthermore it needs relatively less information about the system and also is insensitive to the parametrical changes plus it doesn't need the mathematical models accurately like classical controllers but needs the range of parameter changes for ensuring sustainability and condition satisfactory [25, 30-32]. The SMC goes through three steps:

\section{Choice of surface}

Sliding surface as shown in (17): 


$$
S=\omega_{r}-\omega_{\text {ref }}, S_{1}=i_{q}-i_{\text {qref }}, S_{2}=i_{d}-i_{\text {dref }}
$$

The derivative of (17) as shown in (18):

$$
\dot{S}=\dot{\omega}_{r}-\dot{\omega}_{\text {ref }}, \dot{S}_{1}=\dot{i}_{q}-\dot{i}_{\text {qref }}, \quad \dot{S}_{2}=\dot{i}_{d}-\dot{i}_{\text {dref }}
$$

By substituting ( $\omega_{r}, i_{q}$ and $\left.i_{d}\right)$ in (18), we get (19):

$$
\left\{\begin{array}{l}
\dot{S}=\frac{1}{J}\left(C_{m}-C_{e m}-f \omega_{r}\right)-\dot{\omega}_{r e f} \\
\dot{S}_{1}=-\frac{R_{s}}{L_{q}} i_{q}-\frac{L_{d}}{L_{q}} \omega_{e} i_{d}-\frac{1}{L_{q}} U_{q}+\frac{1}{L_{q}} \phi_{m} \omega_{r}-\dot{i}_{q r e f} \\
\dot{S}_{2}=-\frac{R_{s}}{L_{d}} i_{d}+\frac{L_{q}}{L_{d}} \omega_{r} i_{q}-\frac{1}{L_{d}} U_{d}-\dot{i}_{d r e f}
\end{array}\right.
$$

Convergence condition:

The stability of the SMC is estimated by adopting Lyapunov function as shown in (20).

$$
V=\frac{1}{2} S^{2}
$$

The derivative of (20) as shown in (21):

$$
\dot{V}=S \dot{S} \prec 0
$$

\section{Calculation of control laws:}

Control law has the following form (22),

$$
U=U_{e q}+U_{n}
$$

Where $U$ is the control vector, $U_{e q}$ is the equivalent control vector, we acquire it by considering that $\dot{S}(x)=0 . U_{n}$ Is the switching part of control and it's defined by (23):

$$
U_{n}=k \tanh (S)
$$

Control structure is (24):

$$
\left\{\begin{array}{l}
C_{e m}=C_{m}-f \omega_{r}-J \dot{\omega}_{r e f}+J k \tanh (S) \\
U_{q}=-R_{s} i_{q}-L_{d} \omega_{e} i_{d}+\phi_{m} \omega_{r}-L_{q} \dot{i}_{q r e f}+k_{1} \tanh \left(S_{1}\right) \\
U_{d}=-R_{s} i_{d}+L_{q} \omega_{r} i_{q}-L_{d} \dot{i}_{d r e f}+k_{2} \tanh \left(S_{2}\right)
\end{array}\right.
$$

Where $(\mathrm{k}, \mathrm{k} 1, \mathrm{k} 2)$ are the sliding gain. However, the latter generates on sliding surface, a phenomenon called chattering, which is generally undesirable because it adds to the spectrum control high frequency components as indicate Figure 2, In an attempt to minimize the chattering we will use the hyperbolic tangent function (tanh) which will make the control signal smoother. 


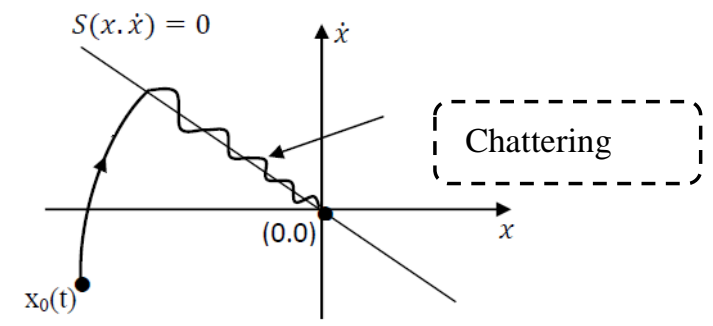

Figure 2. Chattering Phenomenon.

\section{ADAPTIVE SLIDING MODE CONTROLLER}

To bring the rotor speed as quickly as possible to it reference and improve the system's response, the time sliding gain $\mathrm{k}(\mathrm{t})$ is adapted. The control law (24) becomes (25):

$$
C_{e m}=C_{m}-f \omega_{r}(t)-J \dot{\omega}_{\text {ref }}(t)+J k(t) \tanh (S)
$$

The gain adaptation as shown in (26):

$$
k(t)=\int a S \tanh (S) d t
$$

Where, $\alpha$ is a positive adaptation rate. The torque control law has the following expression (27):

$$
C_{e m}=\widehat{C}_{m}-f \omega_{r}(t)-J \dot{\omega}_{\text {ref }}(t)+J k(t) \tanh (S)
$$

Where $\widehat{C}_{m}$ is an estimate of the reflected wind turbine torque. The closed loop dynamics of system (16) and the control law (27) is expressed as shown in (28):

$$
\dot{S}=k \tan (S)+\frac{1}{J} \tilde{C}_{m}
$$

Where $\tilde{C}_{m}=C_{m}-\hat{C}_{m}$ is the torque tracking error. $\tilde{C}_{m}$ must be carried out to reach zero using adaptive estimation of $C_{m}$. Let us impose a first-order dynamics to the torque error as shown in (29):

$$
\dot{\tilde{C}}_{m}+c_{0} \tilde{C}_{m}=0, c_{0} \succ 0
$$

Using the expression of $C_{m}$ and the assumption that $\dot{C}_{m}=0$, (29) is reorganized as (30):

$$
\dot{\bar{C}}_{m}=c_{0}\left(C_{m}-\hat{C}_{m}\right)=c_{0}\left(C_{e m}+f \omega_{r}+J \dot{\omega}_{r e f}\right)-c_{0} \widehat{C}_{m}
$$

Then, the torque control law (27) is substituted into (30) yielding to (31):

$$
\dot{\bar{C}}_{m}=c_{0} J\left(\dot{\omega}_{r}+\dot{\omega}_{r e f}\right)+c_{0} J k \tanh (S)
$$

Integrating (31), the torque estimation becomes (32): 


$$
\dot{\bar{C}}_{m}=c_{0} J S(t)+c_{0} J \int k(t) \tanh (S(t))
$$

To control the stator current components, a field orientation approach is implemented, where the required components of the converter voltage vector are derived from controllers to track $i_{d}^{*}=0$ and $i_{q}^{*}$ carried out from the decoupling turbine-generator, the torque generator is simplified as shown in (33-34):

$$
C_{e m}=\frac{3}{2} p \phi_{m} i_{q}
$$

Therefore, $i_{q s}^{*}$ is:

$$
i_{q}^{*}=\frac{2}{3 p \phi_{m}} C_{e m}^{*}
$$

Where, $C_{e m}^{*}$ is carried out from (27).

\section{SIMULATION RESULTS}

In this section, simulation tests have been performed with the help of Matlab to prove the efficiency of the controller reference tracking. In order to evaluate the control strategy proposed in this paper, a change in wind speed is applied as presented in Figure 3, 4, 5, 6, 7, dan 8.

Figure 4 shows that the rotational speed response converges perfectly to its reference track and following the maximum power. The currents id - iq are depicted in Figures 5 and 6, respectively. It can be seen that the direct and quadrature currents tracks almost perfectly there references which indicate that the ASMC has a good dynamic response, the active power is shown in (7-a). Furthermore, (7-b) shows that the reactive power is approximately zero. Although wind variation, pitch control has a rapid angle respond and minimum power ripples. The mechanical speed of the turbine represented in Figure. 4 is obtained according to angle variation in (8-a). We can notice that the dynamic response of the active power and reactive power under ASMC control is fast and have smooth control signals.
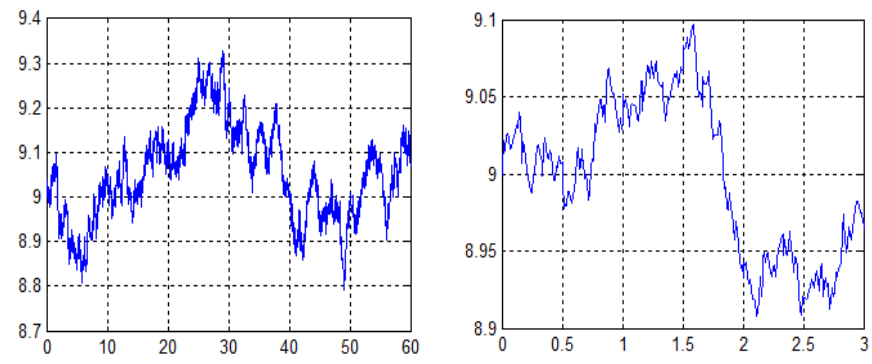

Figure 3. Wind speed
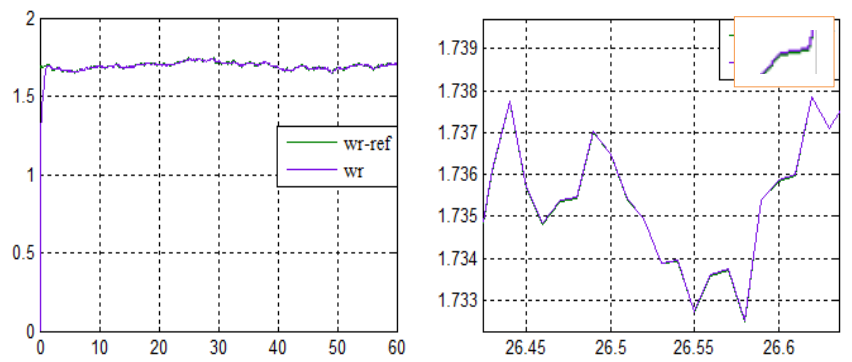

Figure 4. Rotational speed $\omega r$ 

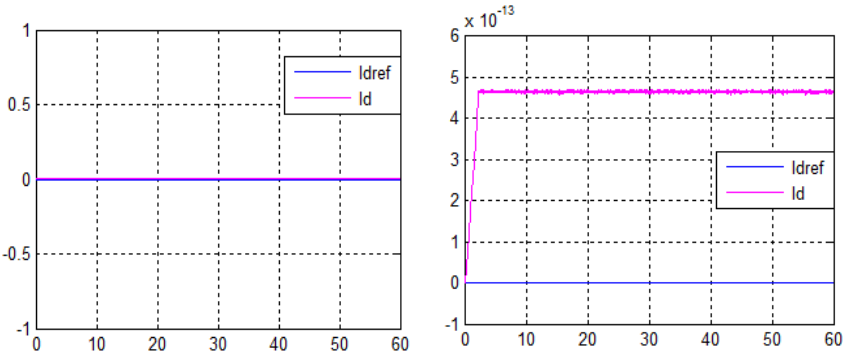

Figure 5. Direct current Id
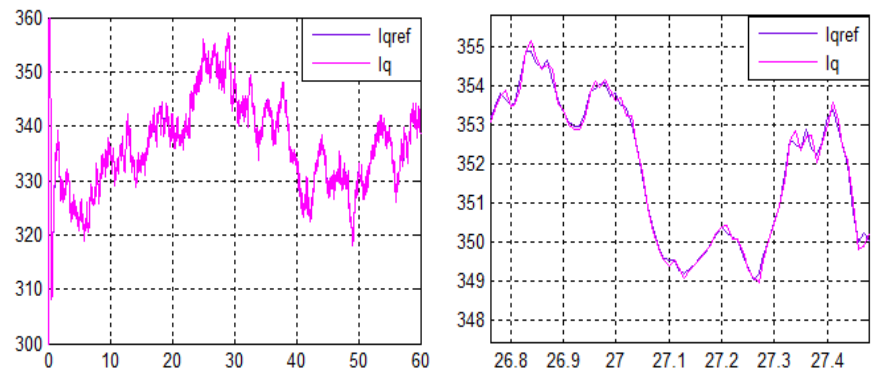

Figure 6. Quadrature current Iq

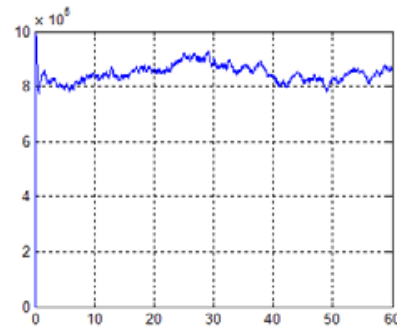

(a)

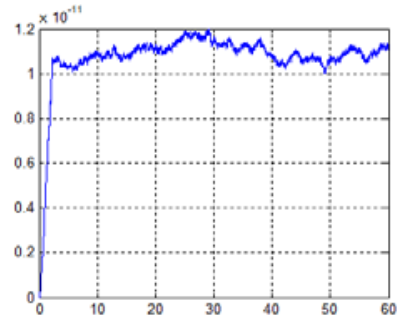

(b)

Figure 7. a-Active power b-Reactive power

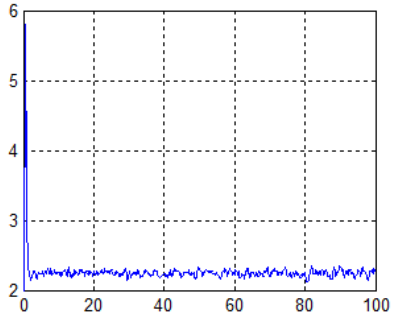

(a)

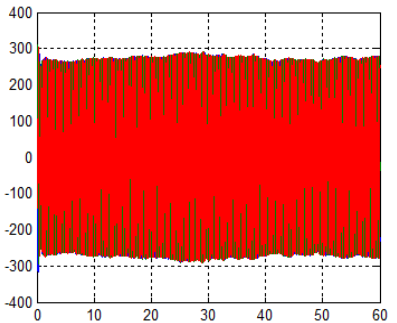

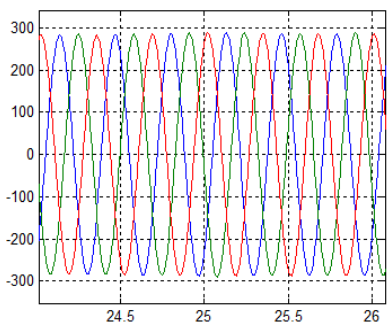

(b)

Figure 8. a-Pitch angle b-Stator courant

\section{CONCLUSION}

This paper was devoted to modelling, control and simulation of a wind turbine used the PMSG running at variable speed, A pitch angle controller has been added to regulate the electric power, it allows to lower the excess power and keep it constant to ensure the continuity of the production of electrical energy, simulation results indicate that the ASMC provides a notable efficiency, since it permits to track the optimum power quickly despite the speed wind changing, external disturbances and the parametric variations. On the other hand, the stator power quantities provided show smooth waveforms, with good tracking indices. Consequently, undesirable mechanical stresses and the chattering in the case of SMC are avoided. 


\section{REFERENCES}

[1]. Phan DH, Huang S (2015) Super-Twisting Sliding Mode Control Design for Cascaded Control System of PMSG Wind Turbine. Journal of Power Electronics 15 (5):1358-1366.

[2]. Jadhav HT, Roy R (2013) A Comprehensive Review on the Grid Integration of Doubly Fed Induction Generator. International Journal of Electrical Power \& Energy Systems 49:8-18. doi:https://doi.org/10.1016/j.ijepes.2012.11.020.

[3]. Abdeddaim S, Betka A (2013) Optimal Tracking and Robust Power Control of the DFIGURE Wind Turbine. International Journal of Electrical Power \& Energy Systems 49:234-242.

[4]. López EC, Persson J (2012) High-Order Models of Doubly Fed Induction Generators. In: Wind Power in Power Systems. John Wiley \& Sons, Ltd, pp 849-864. doi:10.1002/9781119941842.ch37.

[5]. Yamamoto M, Motoyoshi O Active and Reactive Power Control of Doubly-Fed Wound Rotor Induction Generator. In: 21st Annual IEEE Conference on Power Electronics Specialists, 0-0 1990 1990. pp 455-460. doi:10.1109/PESC.1990.131223.

[6]. Yang W, Tavner PJ, Crabtree CJ, Feng Y, Qiu Y (2014) Wind turbine condition monitoring: technical and commercial challenges. Wind Energy 17 (5):673-693.

[7]. Semken RS, Polikarpova M, Röyttä P, Alexandrova J, Pyrhönen J, Nerg J, Mikkola A, Backman J (2012) Directdrive permanent magnet generators for high-power wind turbines: Benefits and limiting factors. IET Renewable Power Generation 6 (1):1-8.

[8]. Nguyen TH, Lee D-C (2013) Advanced Fault Ride-Through Technique for PMSG Wind Turbine Systems Using Line-Side Converter as STATCOM. IEEE transactions on industrial electronics 60 (7):2842-2850.

[9]. Li S, Haskew TA, Xu L (2010) Conventional and Novel Control Designs for Direct Driven PMSG Wind Turbines. Electric Power Systems Research 80 (3):328-338.

[10]. Merzoug M, Benall H, Louze L (2012) Sliding Mode Control (SMC) of Permanent Magnet Synchronous Generators (PMSG). Energy Procedia 18:43-52.

[11]. Hung JY, Gao W, Hung JC (1993) Variable Structure Control: A survey. IEEE transactions on industrial electronics 40 (1):2-22.

[12]. Emna ME, Adel K, Mimouni MF (2013) The Wind Energy Conversion System Using PMSG Controlled By Vector Control and SMC Strategies. International Journal of Renewable Energy Research 3 (1):41-50.

[13]. Valenciaga F, Puleston PF (2008) High-Order Sliding Control for a Wind Energy Conversion System Based on a Permanent Magnet Synchronous Generator. IEEE Transactions on Energy Conversion 23 (3):860-867. doi:10.1109/TEC.2008.922013.

[14]. Karim B, Sami BS, Adnane C Higher Order Sliding Mode Control for PMSG in Wind Power Conversion System. In: Control Engineering \& Information Technology (CEIT), 2016 4th International Conference on, 2016. IEEE, pp 1-5.

[15]. Gu P, Wang X, Reitz M High Order Sliding Mode Control of Permanent Magnet Synchronous Generator-Based Wind Energy Conversion Systems. In: 2016 IEEE Energy Conversion Congress and Exposition (ECCE), 18-22 Sept. 2016 2016. pp 1-8. doi:10.1109/ECCE.2016.7855409.

[16]. Sabzevari S, Karimpour A, Monfared M, Naghibi Sistani MB (2017) MPPT Control of Wind Turbines By Direct Adaptive Fuzzy-PI Controller and Using ANN-PSO Wind Speed Estimator. Journal of Renewable and Sustainable Energy 9 (1):013302.

[17]. Lee C-Y, Shen Y-X, Cheng J-C, Li Y-Y, Chang C-W (2009) Neural Networks and Particle Swarm Optimization Based MPPT for Small Wind Power Generator. World Academy of Science, Engineering and Technology 60 (2009):17-23.

[18]. Abdullah MA, Yatim A, Tan C, Saidur R (2012) A Review of Maximum Power Point Tracking Algorithms for Wind Energy Systems. Renewable and sustainable energy reviews 16 (5):3220-3227.

[19]. Wang G-D, Wai R-J, Liao Y (2013) Design of Backstepping Power Control for Grid-Side Converter of Voltage Source Converter-Based High-Voltage Dc Wind Power Generation System. IET Renewable Power Generation 7 (2):118-133.

[20]. Dongliang L, Xiehui Z, Lili C (2011) Backstepping Control of Speed Sensorless Permanent Magnet Synchronous Motor. Transactions of China Electrotechnical Society 26 (9):67-72.

[21]. Krstic M, Kanellakopoulos I, Kokotovic PV (1995) Nonlinear and Adaptive Control Design. Wiley.

[22]. Morshed MJ, Fekih A (2017) A New Fault Ride-Through Control for DFIGURE-Based Wind Energy Systems. Electric Power Systems Research 146:258-269. doi:https://doi.org/10.1016/j.epsr.2017.02.010.

[23]. Njiri JG, Söffker D (2016) State-of-The-Art In Wind Turbine Control: Trends and challenges. Renewable and Sustainable Energy Reviews 60:377-393. doi:https://doi.org/10.1016/j.rser.2016.01.110.

[24]. Abad G, López J, Rodríguez MA, Marroyo L, Iwanski G (2011) Direct Control of the Doubly Fed Induction Machine. In: Doubly Fed Induction Machine. John Wiley \& Sons, Inc., pp 363-477. doi:10.1002/9781118104965.ch8.

[25]. Alaya JB, Khedher A, Mimouni MF Nonlinear Vector Control Strategy Applied to a Variable Speed DFIGURE Generation System. In: Eighth International Multi-Conference on Systems, Signals \& Devices, 22-25 March 2011 2011. pp 1-8. doi:10.1109/SSD.2011.5767498.

[26]. Luna A, Lima FKA, Rodriguez P, Watanabe EH, Teodorescu R Comparison of Power Control Strategies for DFIGURE Wind Turbines. In: 2008 34th Annual Conference of IEEE Industrial Electronics, 10-13 Nov. 2008 2008. pp 2131-2136. doi:10.1109/IECON.2008.4758286. 
[27]. Li S, Haskew TA, Swatloski RP, Gathings W (2012) Optimal and Direct-Current Vector Control of Direct-Driven PMSG Wind Turbines. IEEE Transactions on Power Electronics 27 (5):2325-2337. doi:10.1109/TPEL.2011.2174254.

[28]. Lopez J, Sanchis P, Roboam X, Marroyo L (2007) Dynamic Behavior of the Doubly Fed Induction Generator During Three-Phase Voltage Dips. IEEE Transactions on Energy Conversion 22 (3):709-717. doi:10.1109/TEC.2006.878241.

[29]. Ayadi M, Salem FB, Derbel N Sliding Mode Approach for Blade Pitch Angle Control Wind Turbine Using PMSG Under DTC. In: Sciences and Techniques of Automatic Control and Computer Engineering (STA), 2015 16th International Conference on, 2015. IEEE, pp 758-762.

[30]. Shtessel Y, Edwards C, Fridman L, Levant A (2013) Sliding Mode Control and Observation. Springer New York.

[31]. Slotine JJE, Li W (1991) Applied Nonlinear Control. Prentice-Hall.

[32]. Yang B, Jiang L, Wang L, Yao W, Wu QH (2016) Nonlinear Maximum Power Point Tracking Control and Modal Analysis of DFIGURE Based Wind Turbine. International Journal of Electrical Power \& Energy Systems 74:429436. doi:https://doi.org/10.1016/j.ijepes.2015.07.036. 